\title{
Los vaivenes del rupturismo en la epistemología de
} Martínez Escárcega

\author{
Leonardo Meza Jara \\ Universidad Pedagógica Nacional del Estado de Chihuahua \\ Campus Chihuahua
}

\section{Resumen}

E

ste ensayo hace una revisión crítica del libro "La epistemología rupturista. Reflexiones sobre un psicoanálisis del objeto" (Martínez Escárcega, 2011). Se toma como eje la idea de "ruptura epistemológica", la cual constituye el núcleo teórico e ideológico del libro analizado. En la primera parte se revisan los orígenes de este concepto. Más allá del territorio de la epistemología de la ciencia, se concibe a la ruptura epistemológica como una forma de producción cultural de la modernidad, que fija su creencia en la renovación constante de las formas de vida. En la segunda parte, se analizan los mecanismos a través de los cuales la ruptura epistemológica se convierte en una herramienta teórica fundamental del marxismo althusseriano, que pretende darle forma a una ciencia de corte marxista. Siendo el alma del libro de Martí- nez Escárcega, la ruptura epistemológica se analiza desde diversos ángulos, poniendo en claro las conexiones del libro con diversos autores, teorías y formas de pensamiento que han sido parte del desarrollo de la ciencia en las últimas décadas.

Palabras clave: ruptura epistemológica, modernidad, marxismo y sobredeterminación.

\section{I}

Apoyándose en Freud y en Lacan, en el libro "La epistemología rupturista. Reflexiones sobre un psicoanálisis del objeto" Martínez Escárcega (2011)desarrolla un psicoanálisis del objeto de estudio científico, que cuestiona los mecanismos epistemológicos positivistas de la investigación en las ciencias sociales. Al lado del psicoanálisis, este texto asume los aportes que la teoría crítica elabora desde el marxismo, 
planteando la necesidad de racionalizar de una manera alterna el tratamiento del objeto de estudio. Desde esta perspectiva, Martínez Escárcega no hace aportes relevantes en los debates que han tenido lugar en la epistemología de las ciencias sociales en las décadas recientes, entre las formas de pensamiento que se agrupan en los polos del positivismo y la teoría crítica marxista.

La tesis central de este libro plantea un aparato teórico que busca revitalizar la idea de la "ruptura epistemológica". Al analizar este texto, las primeras preguntas que surgen tienen que ver con la formación de esta manera de pensar, como una forma de racionalización específica. ¿Qué es la "ruptura epistemológica"? ¿Cómo emerge esta idea a lo largo del siglo XX? ¿Cómo esta forma de pensamiento se construye a partir de un correlato entre la epistemología científica y la teoría crítica derivada del marxismo? ¿Cuáles son sus componentes filosóficos, políticos y culturales?

De inicio, se detectan tres cualidades que se hacen presentes en el surgimiento de esta idea a lo largo del siglo XX:

1) De manera germinal la "ruptura epistemológica" toma forma en el solo terreno de la epistemología de la ciencia, a partir de los aportes de Bachelard, principalmente en el libro "La formación del espíritu científico. Contribución a un psicoanálisis del conocimiento objetivo" (2000).

2) Durante la segunda mitad del siglo $\mathrm{XX}$, el posicionamiento teórico de mayor peso de esta idea, tiene lugar desde de los aportes de la teoría críti- ca (Athusser y Balibar, fundamentalmente). Hay entonces un andamiaje teórico-político-ideológico, a través del cual la "ruptura epistemológica" se traslada del campo de la epistemología de la ciencia, a un territorio de convergencia con la teoría marxista.

3) El planteamiento de Martínez Escárcega surge tanto de los aportes de Bachelard como de los planteamientos de la teoría crítica. La propuesta descansa sobre una trabazón disciplinaria, entre los territorios de la epistemología de la ciencia, el psicoanálisis, la filosofía, y la teoría política y social de corte marxista. Esta trama teórica resulta conflictiva.

En los apartados siguientes se analizan las tres cualidades descritas.

\section{II}

La idea de la ruptura epistemológica posee un origen intrincado a lo largo del siglo XX. Este concepto no fue planteado estrictamente por Bachelard, aunque suele atribuírsele a este filósofo de la ciencia y la literatura, una especie de paternidad conceptual. Gassmann (2013:37) afirma que Bachelard no cita de manera puntual el término, sino que refiere conceptos como: "romper", "ruptura", "revolución", "novedad total", "brusca mutación espiritual", "división en el campo del espíritu científico", etc. Puede afirmarse, que de manera germinal el concepto de "ruptura epistemológica" está ya presente en Bachelard, aunque aún carente de la inclinación ideológica que tomaría posteriormente en los caminos de la teoría crítica de herencia marxista. 
Para Bachelard, la idea de la "ruptura" en el campo de la epistemología científica, está íntimamente conectada con el concepto de "obstáculo epistemológico". El obstáculo epistemológico llama a una intervención que lo rebase, que lo ponga en jaque, para que la ciencia pueda proseguir su camino positivizado a toda costa. Uno de los mecanismos a través de los cuales la ciencia puede luchar en contra de los obstáculos epistemológicos es el rupturismo. El primer obstáculo epistemológico que la ciencia debe tomar en cuenta es el conocimiento de sentido común, las experiencias de la vida diaria que son una forma de saber no racionalizado ni sistematizado científicamente. Lecourt (2013:26) afirma que aunque el obstáculo epistemológico es "polimorfo", funciona en un solo sentido, en un "sentido contrario al "No"», rellenando los espacios rotos que se abren entre conocimiento común y conocimiento científico, y revitalizando a "la continuidad amenazada por el progreso del conocimiento científico".

En la formación del espíritu científico, el primer obstáculo es la experiencia básica, es la experiencia colocada por delante y por encima de la crítica, que, esta sí, es necesariamente un elemento integrante del espíritu científico... He aquí entonces la tesis filosófica que sostendremos: el espíritu científico debe formarse en contra de la Naturaleza, en contra de lo que es, dentro y fuera de nosotros, impulso y enseñanza de la Naturaleza, en contra del entusiasmo natural, en contra del hecho coloreado y vario. El espíritu científico debe formarse reformándose (Bachelard, 2000:27).
La ruptura epistemológica es un mecanismo de defensa que le resulta sustantivo al quehacer científico, es una especie de vitalismo que acompaña a la constante restauración de esta actividad. Para Bachelard, la ruptura epistemológica es parte de la formación del espíritu científico, como un mecanismo de renovación inagotable. Aunque el concepto de "espíritu científico" resulta difuso en Bachelard, queda claro que esta forma de espiritualidad se ancla en un llamamiento continuo a la renovación: "El espíritu científico debe formarse reformándose" en lucha con los obstáculos epistemológicos, que lo mismo pueden tener lugar en el conocimiento de sentido común, que en una racionalidad científica agotada y reformulada por una nueva racionalidad, como es el caso de la teoría de la relatividad de Einstein, que replantea el pensamiento de la física y de la astronomía dominado durante décadas por la herencia fijada por Newton.

La idea de la ruptura epistemológica forma parte del espíritu histórico-cultural que hemos heredado de la modernidad, aunque su genealogía puede rastrearse hasta los orígenes de la civilización occidental. Una de las mayores cargas ideológicas que hemos heredado de la modernidad consiste en renovarse o morir. Romper con lo ya establecido para instaurar una nueva forma, que a su vez, será reemplazada por otra más. No es coincidencia que el momento histórico en el que emerge el rupturismo epistemológico, sea el mismo en el que tiene lugar la crisis del modernismo artístico, que desemboca en el posmodernismo. Lypovetsky (2008:81) analiza el correlato que existe entre el capitalismo 
y el modernismo en el arte. Entre 1880 y 1930 , la tendencia de un vanguardismo inagotable se establece como ideología de la producción artística. El modernismo deja de preocuparse por la sola variación estilística y temática, pretende romper con la continuidad que se ancla en lo ya creado y acontecido, dándole forma a la creación de obras totalmente nuevas. Crear a toda costa para renovar y renovar a toda costa para crear. El devenir de las vanguardias que sustituyen a otras, es el camino trazado para el arte, que fijado en la posibilidad de la renovación infinita, lleva consigo los signos de la decadencia.

El espíritu científico del cual nos habla Bachelard, como una forma de renovación infinita del quehacer científico, es parte del mismo núcleo ideológico de renovación vanguardista en el arte, que pasa del modernismo al posmodernismo. Aunque habría que subrayar las diferencias entre ambos. Mientras el espíritu científico pretende una renovación que se inscribe en un tiempo histórico de larga duración (como es el caso del paradigma de Newton o de Einstein, que permanecen o pueden permanecer durante décadas y/o siglos, antes de ser refutados y replanteados), el espíritu de renovación artística, se asfixia en lo acontecimental, en lo no duradero que incita a lo efímero. Hablamos de formas de producción de la cultura, que en la ciencia, en el arte y en otros territorios del saber, tienen que ver con los debates entre la modernidad y la posmodernidad, en este caso, a partir de la idea de la ruptura epistemológica, como una forma de renovación permanente.
En este sentido, cuando Balibar (1994: 72) lanza la pregunta ¿Qué es una ruptura?, pone en claro que hay dos maneras de responder la interrogante. La primera tiene que ver con la idealidad de una ruptura única, sujeta de una "descripción inmanente" y una epistemología interiorizada en sí misma. La segunda remite a rupturas múltiples, sobre las que habrá que fijar la mirada más en las diferencias que en las estructuras epistemológicas que comparten. En el fondo, Balibar se pregunta si el rupturismo científico ha de ser moderno, anclado en una estructura de dominación tan perdurable que nos lleve a entenderlo como "inmanente", o si ha de ser posmoderno, sujeto de la multiplicidad y la diferencia. ¿Una forma de ruptura que daría lugar a un dominio epistemológico de larga duración, que en el desarrollo de la ciencia nos lleve a imaginar su "inmanencia" y que de esta manera lleve a una contracción de la ruptura? ¿O una serie de dominios epistemológicos en constante pugna, que sin estar fijados en absoluto alguno, configuran una diversidad epistemológica en constante conflicto, dando pie a la expansión de la tendencia rupturista?

Balibar asume que los dos mecanismos de desarrollo de la ciencia resultan necesarios, de tal forma que el segundo lleve a la corrección del primero. Esto pone en claro a la dialéctica del desarrollo del pensamiento científico, que se fortalece a lo largo del siglo XX. Por un lado, está la tendencia a una dureza epistemológica que se sostenga en la perdurabilidad de la verdad, por otro lado, está la posibilidad de trastocar a esta verdad no plenamente perdurable, para 
instaurar una nueva formación de la verdad. El abordaje del capítulo final del libro de Martínez Escárcega ("Discontinuidad y ruptura”, p:177-188) el cual conceptualiza a la "continuidad" y la "discontinuidad" epistemológica, resulta idéntico al planteamiento analizado en Balibar:

La epistemología continuista es la visión hegemónica en la filosofía de la ciencia... La visión continuista se enmarca en una posición teleológica sobre el desarrollo científico, donde la historia obedece a una linealidad de progreso previamente establecido... La discontinuidad sería la principal característica del pensamiento científico, al tratar de hallar en cada pensador el potencial de una revolución científica... La epistemología rupturista emplea tanto la lógica continuista como la discontinuista, dando forma a una nueva lógica psicoanalítica, en la cual el objeto es producto de una construcción teórica en confrontación con su manifestación empírica deformada.

Para Martínez Escárcega, concebidas por separado, tanto la epistemología continuista como la discontinuista constituyen un obstáculo epistemológico. Pero puestas una al lado de la otra, le dan forma una "epistemología rupturista" enclavada en el psicoanálisis del objeto de estudio y en la carga crítica de la teoría marxista. Este planteamiento se inserta en una lógica científica que se decanta a lo largo del siglo $\mathrm{XX}$ y que aquí ha sido nombrada como: la dialéctica del desarrollo del pensamiento científico.

Esta dialéctica del desarrollo científi$\mathrm{co}$, en tanto forma de pensamiento que se enraíza más allá de los linderos de la epis- temología de la ciencia, es un territorio en el que confluyen de maneras diferentes Bachelard, Popper, Balibar y Martínez (estos dos últimos, como integrantes de la corriente de la teoría crítica). No se está admitiendo la presencia de una armonía o de una conexión directa entre los autores mencionados, en los términos teóricos y/o ideológicos de la epistemología científica. Desde luego que hay diferencias insalvables entre ellos. Bachelard rechaza al positivismo al hacer una crítica enfática del "espíritu científico", a la vez, este autor resulta lejano del marxismo. Popper choca de manera determinante con la postura bachelardiana y con la teoría crítica. Por su parte, los autores de la teoría crítica abrevan de Bachelard, dando una vuelta de tuerca y llevando su teoría al núcleo ideológico del marxismo, a la vez que lanzan diatribas contra los positivistas.

El triángulo teórico que se analiza en esta parte para poner en claro a la dialéctica del desarrollo del pensamiento científico (Bachelard, Popper y los integrantes de la teoría crítica) parece tomar la forma de una intriga, propia de una novela habitada por héroes que a la vez pueden ser concebidos como antihéroes, todo depende del lugar teórico y/o ideológico desde el cual se considere el asunto. Las genealogías del pensamiento se complejizan cuando los marcos de análisis suelen salirse de los estrictos territorios disciplinarios.

La crítica que Bachelard lanza sobre el "espíritu científico" en tanto su renovación infinita, el doble movimiento señalado por Balibar y reiterado por Martínez Escárcega, sobre un desarrollo epistemológico sus- 
tentable y de larga duración, que a su vez, queda sujeto en cualquier momento a la posibilidad de un relevo en sus formas de admitir la verdad, y el falsacionismo de Popper que plantea una renovación constante de la ciencia en el ir y venir de la verdad y el error, señalan una forma de pensamiento que surge en el tiempo histórico de la modernidad, señalan las huellas de un núcleo ideológico que se sostiene en la postulación de una renovación constante, no solo en el campo de la epistemología científica, sino en el territorio mucho más amplio de la producción de la cultura. Renovarse o morir, trastocar lo viejo para dar lugar a lo nuevo que viene signado como un mensaje de redención y salvación. El pensamiento utópico y el pensamiento mítico se hacen presentes aquí. Esta tendencia renovadora, que busca una reinstauración del mundo a través del saber, no pertenece estrictamente al pensamiento moderno. Analizando los aportes de Toynbee sobre la desintegración y el surgimiento de las civilizaciones, Campbell (1972:17) revisa el concepto de "palingenesia":

Solo el nacimiento puede conquistar la muerte, el nacimiento, no de algo viejo, sino de algo nuevo... Porque por medio de nuestras victorias, si no sufrimos una regeneración, el trabajo de Némesis se lleva a cabo: la perdición nace del mismo huevo que nuestra virtud. Así resulta que la paz es una trampa, la guerra es una trampa, el cambio es una trampa, la permanencia es una trampa. Cuando llegue nuestro día por la victoria de la muerte, la muerte cerrará el círculo; nada podemos hacer, con excepción de ser crucificados y resucitar; ser totalmente desmembrados y luego vueltos a nacer.
La persecución incesante del nacimiento de lo nuevo como una forma de transformación material, psicológica o espiritual del mundo, es una tendencia que puede rastrearse tanto en las filosofías orientales como occidentales. Los rituales antiguos de la palingenesia, como una constante recurrencia del nacimiento que pueda nulificar los amenazantes vaivenes de la muerte, se han transformado a lo largo de los siglos y se configuran de manera sui generis en los tiempos modernos.

Dentro de la ciencia, hay componentes que no son estrictamente científicos, que no son parte del núcleo duro de la epistemología científica. El minucioso análisis teórico que hace Bachelard en "La formación del espíritu científico" (2004:12), da cuenta de cómo lo científico se entremezcla con lo no científico. Bachelard nos habla de un sustento no científico de la ciencia, de un territorio de sombras y claroscuros, poblado de figuras psicológicas, estéticas y metafísicas. A esto se refiere con el término de "espíritu científico". Desde la perspectiva dura de la epistemología de la ciencia, los conceptos de "ciencia” y "espíritu” están separados por un abismo imposible de ser superado. Desde la revisión que realiza $\mathrm{Ba}$ chelard, ambos conceptos convergen en un territorio científico-no-científico, que ha intentado ser depurado y que es negado a toda costa.

Nunca como en nuestra época el espíritu científico necesita ser defendido, ser ilustrado...Pero tal ilustración no puede limitarse a una sublimación de las aspiraciones comunes más diversas. Ella debe ser normativa y coherente. Debe tomar claramente 
consciente y activo el placer de excitación espiritual en el descubrimiento de la verdad. Debe forjar la mente con la verdad. El amor por la ciencia debe ser un dinamismo psíquico autógeno. En el estado de pureza logrado por un psicoanálisis de un conocimiento objetivo, la ciencia es la estética de la inteligencia. (Cursivas de origen).

Recurriendo al planteamiento de Bachelard, habría que preguntarse por las cualidades específicas de la epistemología rupturista de Martínez Escárcega, en tanto una forma de pensamiento que desde el territorio de la epistemología de las ciencias sociales "estetiza a la inteligencia" mediante una serie de mecanismos expositivos que defienden unas tesis, ponen en claro un cúmulo de conceptos y recurren a diversas formas de argumentación.

Hay una "estética de la inteligencia" en el libro de Martínez Escárcega. El alegato epistemológico de este autor se inserta en la autoinstauración y autodefensa del pensamiento científico como verdad incuestionable. Una defensa del pensamiento se realiza desde la interioridad misma del pensamiento que se defiende. Martínez Escárcega evita preguntarse con la suficiente dureza crítica sobre el papel que tendría que jugar la filosofía ante la ciencia, enseguida convierte a su filosofar en servidumbre de la ciencia, la filosofía como sierva del quehacer científico.

Hay una distancia enorme entre el "psicoanálisis del conocimiento objetivo" de Bachelard y el "psicoanálisis del objeto de estudio" planteado por Martínez Escárcega. Bachelard levanta su discurso desde una exterioridad de la ciencia, su filosofía deconstruye al pensamiento científico desde un afuera. El conocimiento objetivo psicoanalizado por el epistemólogo francés, nos hace ver los fantasmas y los monstruos que se levantan alrededor del quehacer científico. Por su parte, desde los adentros de la ciencia, Martínez Escárcega psicoanaliza al objeto de estudio para purificarlo de los obstáculos epistemológicos que le resulten estorbosos. El teórico mexicano le abona al constructivismo científico, defiende al pensamiento científico como un espacio legítimo de construcción del saber. Entre las estrategias psicoanalíticas de Bachelard y de Martínez Escárcega, hay una distancia teórica e ideológica que no se pone en claro en el libro del segundo.

Resulta extraño que Martínez Escárcega (2011:188) entre sus múltiples citaciones, haga uso de una referencia del libro "La arqueología del saber" de Michael Foucault, intentando fortalecer mediante la estrategia argumentativa de la autoridad intelectual su idea del rupturismo epistemológico. En términos foucaultianos, mientras Martínez Escárcega positiviza el rupturismo del saber, defendiendo una manera específica de hacer ciencia desde los adentros de la actividad científica, Foucault crítica férreamente a las formaciones de la verdad, desde una filosofía externa a la ciencia, que cuestiona las configuraciones histórico-filosóficas de la "episteme". Mientras la postura de Martínez Escárcega postula un constructivismo científico de corte rupturista, Foucault deconstruye al pensamiento científico (y a otras formas de pensamiento) como una formación del saber inscrito 
en una historia y en una serie de procedimiento discursivos que resultan cuestionables. Para Martínez Escárcega, la ruptura pertenece al orden de la renovación científica moderna a través de la fe que se deposita en la utopía. Para Foucault, la ruptura es parte de los mecanismos y estratagemas que configuran los dominios del saber:

La puesta en juego de los conceptos de discontinuidad, de ruptura, de umbral, de límite, de serie, de transformación, plantea a todo análisis histórico no solo cuestiones de procedimientos, sino problemas teóricos. Son estos problemas los que van a ser estudiados aquí... Hay que realizar ante todo un trabajo negativo: liberarse de todo un juego de nociones que diversifican, cada una a su modo, el tema de la continuidad... Es preciso desalojar esas formas y esas fuerzas oscuras por las que se tiene costumbre ligar entre sí los discursos de los hombres; hay que arrojarlas de la sombra en la que reinan (2006:33 y 35$)$.

En "La arqueología del saber", Foucault pone en claro los mecanismos a través de los cuales se erigen las formaciones de la verdad, en términos históricos y discursivos. En este libro, Foucault (24-25) revisa como procedió su análisis en tres obras anteriores: "Historia de la locura" "El nacimiento de la clínica" y "Las palabras y las cosas". Los desdoblamientos de la arqueología del saber quedan explicados aquí, como una intrincada manera de analizar las formaciones del saber, no como un método en sí mismo. El concepto de "ruptura" es entonces sometido a una crítica como parte de las figuras de instauración y amansamiento de la verdad.
Se hace necesario psicoanalizar no al objeto de estudio, tal como lo hace Martínez Escárcega, sino psicoanalizar, historizar y filosofar al quehacer científico en su conjunto, en todos y cada uno de sus fundamentos, desde el exterior del edificio de la arquitectura científica, tal como queda manifiesto en el pensamiento de Bachelard y de Foucault, aunque por caminos totalmente diferentes. En las maneras de reflexionar y cuestionar las formaciones del saber no hay rutas trazadas de antemano, está es una de las grandes enseñanzas de la filosofía francesa en el siglo XX, entre los andaderos que van de Bachelard hasta Foucault.

\section{III}

Mediante el concepto de "ruptura epistemológica", Bachelard hace una crítica enfática al quehacer científico del orden positivista, pero no desde el marxismo. Bachelard no es marxista. Cuando Lecourt analiza los aportes de Bachelard para inscribirlos en una crítica marxista de la epistemología, reconoce la presencia de un forzamiento teórico, aunque a fin de cuentas justifica el procedimiento (2013:19).

El traslado de la idea de la "ruptura epistemológica" desde Bachelard hasta la teoría crítica marxista, tiene lugar en un territorio de claroscuros. Althusser toma la idea de Bachelard, llevándola a su propio debate marxista. En su lectura de Marx, Althusser pretende una reinterpretación del marxismo que hacia las décadas de 1960 y 1970 resulta innovadora. La pregunta que asedia a la obra de Althusser es un entrecruce entre el marxismo y la ciencia:¡Cómo el mar- 
xismo puede constituirse en una maquinaria teórica que pueda ser sustentable en una cientificidad propia, que pueda debatir, contrarrestar y sustituir a las formas de pensamiento y de vida que confluyen entre el positivismo y el capitalismo?

La "ruptura epistemológica" de Althusser, pretende explicar a partir de le evolución interna de la propia obra de Marx, cómo tiene lugar un quiebre entre el primer Marx (el autor joven aún influenciado por Hegel, el aún instalado en la filosofía como primera crítica de la ideología, el filósofo que todavía no proporciona la materia teórica para darle forma a una estricta cientificidad marxista) y el segundo Marx (el que logra desprenderse de Hegel, el autor de "El capital", una obra que posibilita concebir al marxismo como una forma de pensamiento que abre las puertas hacia una nueva cientificidad, alterna al positivismo y al capitalismo).

La "ruptura epistemológica" de Bachelard es extraterritorial al marxismo, muy lejana de las pretensiones teóricas e ideológicas de esta forma de pensamiento. $\mathrm{La}$ "ruptura epistemológica" de Althusser, es intraterritorial al marxismo, pretende una revitalización del marxismo que se había estancado en los debates revisionistas durante la segunda mitad del siglo XX. A partir de las posturas distintas de Bachelard y de Althusser, no es posible admitir que el segundo lleva a cabo una desviación del concepto originalmente planteado. Los conceptos no son estables ni permanentes. La elaboración de conceptos, tanto en la filosofía como en la ciencia, es parte de una plasticidad que forma parte de las transfor- maciones infinitas del saber. La postura de Althusser resulta válida, y puede entenderse como un procedimiento conceptual que desde el marxismo, teoriza e ideologiza a la "ruptura epistemológica". Esta condición le da forma al núcleo teórico e ideológico del libro de Martínez Escárcega.

El corte que Althusser identifica en Marx, forma parte de una hermenéutica sui generis en la interpretación de la obra del filósofo alemán del siglo XIX. La ruptura epistemológica habita las profundidades de la obra de Althusser en diversos planos. Desde su lectura de Marx, este filósofo da lugar a un primer rompimiento, entre el Marx joven y el Marx maduro que escribe "El capital", para edificar desde esta tesis su propia obra en los debates marxistas. El primer rompimiento-artificioso o no- que Althusser teoriza desde los adentros de la propia obra de Marx, es sintomático de un segundo quiebre, que se manifiesta entre las diversas interpretaciones de la obra de Marx a lo largo del siglo XX.En la filosofía marxista, la obra de Althusser parte de una crítica a las hermenéuticas de Marx ancladas en la tradición del marxismo soviético, que decaen con la muerte de Stalin. Althusser teoriza en pos de la cientificidad del marxismo. Esto implica una ruptura tanto filosófica como ideológica en los debates marxistas. Esta jugada teórica robustece la manera de pensar al marxismo desde la multiplicidad. No hay un marxismo unitario, tal como lo planteó la ortodoxia soviética, sino marxismos diversos o facetas teóricas distintas del marxismo, que a su vez, dan lugar a variadas hermenéuticas del marxismo. El tercer rompimiento 
va de la reinterpretación althusseriana del marxismo, hacia la alianza entre la ciencia positivista y el capitalismo. Una forma de hacer ciencia teorizada desde el marxismo, tendría que sustituir a la ciencia positiva que camina de la mano del capitalismo.

El rupturismo de Althusser, se juega en diversos territorios que son a la vez teóricos, políticos, ideológicos y desde luego históricos. En este ensayo no se pretende analizar los pormenores de estas luchas althusserianas.

A estas alturas cabe preguntarse, ¿ cuál es la forma de la ruptura que se hace presente en la epistemología de las ciencias sociales de Martínez Escárcega? La ruptura epistemológica de este autor es althusseriana y se juega al lado de un soporte teórico del orden psicoanalítico, entre Freud y Lacan.

Dentro de los terrenos de la epistemología de la ciencia, Martínez Escárcega lanza una crítica rupturista en contra del positivismo, que aún posee un dominio significativo en la investigación de las ciencias sociales. La concepción de "ruptura epistemológica" en la obra de Martínez Escárcega, no se plantea con toda entereza ni con toda claridad en el capítulo en el que se lanzan directamente el mayor número de definiciones sobre este término ("Discontinuidad y ruptura": 177-188). El concepto de "ruptura epistemológica" en este autor, se asume de forma indirecta a través del concepto de "sobredeterminación", en los diversos apartados del capítulo "Campo y terreno" (:139-176). La "ruptura epistemológica" es una forma de "sobredeterminación" althusseriana, que se juega en un coctel teórico al lado del psicoanálisis. Tal vez, un segundo título del libro de Martínez Escárcega pudiera ser: «La epistemología "sobredeterminante". Reflexiones sobre "una crítica marxista" del objeto».

En la obra analizada, el término de "ruptura epistemológica" solo toma forma a partir de la idea de "sobrederminación".

Politizar la epistemología no implica asumir una visión economicista y determinista del campo, en donde se supedita el desarrollo del conocimiento científico a las condiciones económicas y sociales en que está inmerso. Si bien se reconoce un papel importante en el desarrollo de la ciencia, el campo científico está sobredeterminado por múltiples factores que, en interacción dialéctica, hacen que emerja una autonomía relativa (Martínez Escárcega, 2011:150).

Desde una postura althusseriana, Martínez Escárcega politiza e ideologiza al quehacer científico, admitiendo que hay una "sobredeterminación" estructural, del orden marxista, que le viene desde lo económico, lo político y lo ideológico.

La formación social es un todo estructural sobredeterminado, donde las estructuras económicas determinan en última instancia a la superestructura política e ideológica. Pero las estructuras de lo político y lo ideológico determinan a su vez a la estructura de lo económico... sin embargo, en toda coyuntura histórica lo económico estructural es el elemento articulador (Ibidem:159).

La noción de sobredeterminación le imprime al campo científico un carácter holístico y complejo. Se puede describir al campo científico como una configuración de relaciones de 
poder territorializadas por diferentes posicionamientos epistemológicos, como un espacio social sobredeterminado de articulación múltiple, donde los intereses epistemológicos y políticos se funden en torno a la lucha por la hegemonía de los principios de legitimidad científica (Ibidem:165).

El planteamiento es marxista y althusseriano. El concepto de "sobredeterminación" de Martínez Escárcega se lee desde el Althusser que escribe "La revolución teórica de Marx", libro publicado en 1965, y que escribe también el capítulo "La inmensa revolución teórica de Marx", que es parte del libro "Como leer El capital", que el autor escribe a dos manos junto con Balibar y que se publica en 1967.

En su remate teórico e ideológico, Martínez Escárcega asume que la sobredeterminación opera como un point de caption lacaniano (Ibidem: 164) a través del cual emerge una postulación del quehacer científico que puede significarse como verdadera en términos marxistas. Líneas más adelante, el autor cita a Žižek, afirmando que la sobredeterminación es un "elemento articulante en un campo ideológico contrahegemónico" como un "posicionamiento anticapitalista".

La sobredeterminación opera teórica e ideológicamente desde el marxismo althusseriano. Desde ahí, en su exposición conceptual y en su argumentación, Martínez Escárcega la hace pasar de manera intrincada a través de Laclau y Moufle (161-163), Lacan (164), Žižek (163-165) y finalmente la hace recaer en Morín (166).
Martínez Escárcega se queda con el Althusser que no ve con claridad las dificultades que tienen lugar en los intentos por llevar el marxismo a los terrenos de la ciencia. Las formas de sustentar teóricamente al marxismo, como un aparato teórico-político-ideológico que permita fundar una cientificidad distinta a la positivista-capitalista, no fructificaron a plenitud en Althusser. En su revisión crítica de la obra de Althusser, Sánchez Vázquez (1975:82-99) admite que a fin de cuentas el filósofo francés no logra escapar del teoricismo. Hay una pregunta planteada por Sánchez Vázquez, que no se contesta de manera satisfactoria a lo largo de la obra de Althusser: “¿cómo puede darse una ciencia instalada en la verdad $y$, sin embargo, vinculada a la lucha de clases?"

El libro de Martínez Escárcega es teoricista. Este aparato teórico que opera postulando una epistemología marxista y psicoanalítica para la investigación en ciencias sociales, comete el mismo error que Althusser, al no poner en claro la forma en que las luchas sociales (la lucha de clases, las luchas étnicas, las luchas culturales, las luchas de género, etc.) se incrustan en la investigación científica, más allá de ser parte de un aparato teórico del orden marxistapsicoanalítico. No hay un lugar concreto de articulación entre las luchas sociales y el aparato teórico propuesto por Martínez Escárcega. Este es un vacío que requiere ser llenado desde un territorio distinto al que el autor elabora desde su libro, tal vez, un territorio que no se inscribe estrictamente en la epistemología de las ciencias sociales. 


\section{IV}

A inicios del siglo XXI, el libro analizado de Martínez Escárcega pertenece a los intentos por revivificar a la teoría marxista. En este estudio solo se ha abordado lo tocante al rupturismo epistemológico, ubicando la reflexión más allá de los linderos de la epistemología de la ciencia y concibiendo a la ruptura como parte de las formas de producción cultural que en la modernidad recurren a la idea de la renovación infinita, en este caso del saber científico.

Se han dejado de lado otras revisiones críticas que pueden hacerse al libro de Martínez Escárcega, como por ejemplo, las formas de argumentación en las que se entrecruzan los territorios de la literatura, el psicoanálisis, la filosofía y la epistemología científica. Tampoco se analiza la intrincada red conceptual que a partir de pares conceptuales le da forma al texto, desde su misma condición capitular (lo oculto y lo visible", "lo observable y la visión", "lo exacto y lo verdadero", "perspectiva y desplazamiento", "la cosa y el objeto", "ideología y realidad", "campo y terreno", "discontinuidad y ruptura").

Se ha revisado lo que se considera el núcleo teórico e ideológico del libro de Martínez Escárcega, que se enraiza en la idea de la "ruptura epistemológica". Se ha afirmado ya, que en el soporte de este concepto subyace la idea de la "sobredeterminación". La "ruptura epistemológica" de Martínez Escárcega, es en el fondo una "sobredeterminación" teórico-ideológica de corte marxista y althusseriana. El mayor desacierto de Martínez Escárcega reside en el intento fallido por erigir una epistemología marxista y althusseriana, que posibilite desarrollar la actividad de la investigación científica en las ciencias sociales, y específicamente en el campo educativo, a partir de una "sobredeterminación", compuesta a la vez de elementos teóricos e ideológicos. La pregunta sobre si es posible conjugar de manera determinante la labor del investigador educativo con las luchas sociales (la lucha de clases, las luchas de género, las luchas étnicas, etc.) no queda respondida con suficiencia en el texto de Martínez Escárcega, que al igual que la obra de Althusser, se extravía en el abordaje teoricista. No necesariamente se requiere un psicoanálisis del objeto de estudio, para sospechar sus condicionamientos positivistas y a la vez capitalistas.

Tal vez, el análisis crítico de un objeto de estudio elaborado desde los aportes del marxismo, pudiera ser desarrollado desde el plano de la sociología, la historia, la filosofía de la cultura y otras disciplinas de las ciencias sociales y las humanidades. Una de las teorías que con más fortaleza ha planteado virajes teóricos de corte marxista desde América Latina, son los estudios poscoloniales, que no se enfrascan únicamente en plantear una epistemología de la investigación científica, sino que aportan críticamente en diversos planos del quehacer académico: la teoría y crítica literaria, la pedagogía, la teoría política, la investigación en ciencias sociales, etc.

El texto de Martínez Escárcega se enfrasca en la epistemología de las ciencias sociales, pretendiendo aportar desde ahí a la investigación educativa. Pero a fin de cuentas, termina asfixiándose teóricamente en los terrenos de la ciencia, donde el 


\section{marxismo ha tenido una presencia margi- nal de manera constante.}

\section{Notas bibliográficas}

1. Los debates entre los teóricos del marxismo y los positivistas, pueden rastrearse hasta la década de 1930, entre los integrantes de la Escuela de Frankfurt y los miembros del Círculo de Viena. El momento más álgido de este debate tuvo lugar en el Congreso de Tubinga de 1961, organizado por la Sociedad Alemana de Sociología. La discusión giró en torno a la fundamentación epistemológica de las ciencias sociales. Del lado de la teoría crítica participaron Theodor Adorno y su discípulo Jurgen Habermas, del lado de los positivistas los protagonistas fueron Karl Popper y su pupilo Hans Albert. Estos debates pueden consultarse en el libro: "La disputa del positivismo en la sociología alemana”, 1973, ediciones Grijalbo, Barcelona, España.

2 La "episteme" es una manera de pensamiento criticada acuciosamente por Foucault, que abre nuevos andaderos en el campo de la filosofía. De manera sintética, Lechuga (2007: 201) refiere que es "una forma de conocimiento o un tipo de racionalidad; es un conjunto de relaciones que pueden unir en una época determinada las prácticas discursivas que originan figuras epistemológicas como las ciencias o los sistemas formalizados." El desarrollo de la ciencia entre los siglos XVIII, XIX y $\mathrm{XX}$, estaría siendo una "episteme", circunscrita a una historicidad, a una serie de formaciones culturales y a unos discursos que pueden ser analizables como formaciones de la verdad. El análisis que Foucault desarrolla sobre la episteme en distintos momentos históricos, se mueve entre la filosofía, la historia, la crítica de la cultura y el análisis del discurso.

\section{Bibliografía}

Althusser, L. (1967) La revolución teórica de Marx. Siglo Veintiuno Editores: México.

Althusser, L. y Balibar, E. (1979) Para leer El capital. Siglo Veintiuno Editores: México.

Bachelard, G. (2000) La formación del espíritu científico. Contribución a un psicoanálisis del conocimiento objetivo. Siglo Veintiuno Editores: México.

Balibar, E. (1995) Nombres y lugares de la verdad. Ediciones Nueva Visión: Argentina.

Campbell, J. (1972) El héroe de las mil caras. Psicoanálisis del mito. Fondo de Cultura Económica: México.

Foucault, M. (2006) La arqueología del saber. Siglo Veintiuno Editores: México.

Gassmann, C. (2013) La ruptura epistemológica según Bachelard, Althusser y Badiou, en: Estudios de epistemología X.Karczmarczyk, P. Comp.p: 9-33.Facultad de Filosofía y Letras de la Universidad Nacional de Tucumán: Argentina.

Lecourt, D. (2013) Para una crítica de la epistemología. Siglo Veintiuno Editores: México.

Lipovetsky, G. (2008) La era del vacío. Editorial Anagrama: España.

Martínez Escárcega, R. (2011) La epistemología rupturista. Reflexiones sobre un psicoanálisis del objeto. Plaza y Valdés Editores e Instituto de Pedagogía Crítica: México.

Sánchez, A. (1975) El teoricismo de Althusser (notas críticas sobre una autocrítica). Consultado en: Revista Cuadernos Políticos. p. 82-99. Ediciones Era: México.

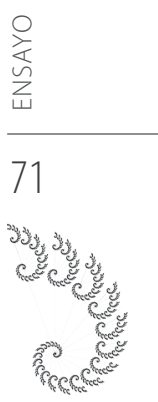

